\title{
Discurso proferido por occasião da collação de gráu aos bacharelandos de 1896 pelo paranympho,- Dr. Pedro Lessa.
}

\author{
Meus jovens collegas.
}

Em uma tarde de maio, entre Vleurgat e a Grande-Espinette, na estrada que de Bruxellas vai á planice inolvidavel de Waterloo, encontram-se dois caminhantes, que por momentos quedam embevecidos na contemplação de singular e esplendido scenario.

Depois de terem percorrido, por entre o mysterioso silencio de uma floresta secular, dilatado trecho em que arvores gigantescas, enlaçando no alto a espessa ramagem, semelham extensa nave rematada em forma de ogiva, sob um tecto de verdura, por onde mal coava esfumada luz crepuscular, subito se lhes rasga uma clara paizagem de horisontes interminos, com deslumbramentos orgiacos de côres, de tons e de luz.

No extremo da floresta, quasi aos pés dos dois caminheiros, troncos de arvores annosas, derruidos no chão, afiguram-se fustes de magestosas columnas com os capitéis despedaçados; além, entremeados de risonhas habitações campezinas, largos tractos de macieiras em flor; depois, uma successão ininterrupta de vejgas, 
levemente onduladas, a que as refracções da luz emprestam o maravilhoso asperto de feericos jardins interminaveis.

No alto, o firmarnento de um azul suave e puro; no horizonte, com tonalidades fulvas de oiro o sol prestes a atufar-se no occaso em meio de uma extranha decoração de phantasticas nuvens brancas.

Aqui, além, por toda a extensão, a febril actividade de uma vida intensa manifestando-se por um incessante formigar de innumeros operarios do campo.

Mudos, immoveis, fitando o mesmo horizonte, os dois viajores pareciam preoccupados pelos mesmos pensamentos, presos das mesmas emoções.

Lentamente, envolvendo em um gesto amplo todo o vasto scenario, interroga um dos personagens:Que divisas?

E o interlocutor a responder:-Nada mais do que linhas e côres, e o pittoresco e a harmonia que resultam do soberbo conjuncto. E tú?-Eu só vejo contractos e direitos.

Tomando nervosamente o braço de quem tão impassivel permanecia diante de tantas bellezas accumuladas pelo esforço artistico do homem e pelas prodigalidades inimitaveis da natureza, prosegue $o$ companheiro, que mal sopeava a natural impaciencia de urn fervoroso cultor das fórmas estheticas:-Vê e admira esta cupula celeste, de um azul tão doce como o olhar meigo de uma joven loira; ao longe, o horizonte de linhas indecisas, tão vago que parece o paiz dos phantasmas; aqui, a herdade com seus grandes muros alvos, flanqueados de arvores floridas, lembrando ramalhetes de orvalhadas flôres perfumosas no cinto de uma camponeza em manhã festiva; mais perto aịnda, esta prodigiosa clareira, tão suggestiva 
que se diria que as faias que estão de pé sobre tres lados de seu quadrilatero, longas filas de guardas avançadas, quaes negros granadeiros a conterem impetuosa multidão em furia, detêm a floresta inteira, que se precipita para vêl-a. Vê, admira. Não sentes a embriaguez das fórmas, das côres, da luz?

-Tu tens o olhar do pintor, e eu o do jurista; não pertenço ao numero das naturezas privilegiadas em cuja mente o bello e o justo se consorciam em seductora e fecunda harmonia; toda esta soberba paizagem apenas me offerece attrahente objecto para o estudo de innumeraveis relações juridicas; de cada um dos seus sitios, de cada um dos seus angulos, os direitos surgem a meus olhos como revoadas de passaros; só vejo a realiclade viva e constante do direito, vastissima teia de fios materialmente invisiveis, tudo penetrando, insinuando-se por toda a parte, adaptando-se a todos os elementos que compõem o extraordinario painel que contemplas inebriado.

"Como o personagem sombrio do admiravel quadro de que minha pobre palavra apenas vos deu um pallido escorço, e que só poude traduzir o talento peregrino de Edmond Picard, o eminente jurisconsulto belga, que é tambem o romancista do direito, eu, desta tribuna junto da qual ainda se ouvem as vibraçōes sonoras da palavra sabia e erudita de tantos mestres que a glorificaram no passado e que e illustram no presente, só vejo direitos e deveres juridicos.

Fallar-vos-ei, pois, mais uma vez, sobre o direito, e na mesma linguagem desataviada a que já deveis estar habituados, tão longo foi o percurso que fizemos juntos no estadio academico.

Mas fallar sobre o direito, meus jovens collegas, é sob um determinado aspecto esflorar todos os problemas que interessam e agitam o individuo, a familia e o Estado. 
Que ha no circulo estreito da mais retrahida e obscura existencia individual, nas puras alegrias e nas tragedias angustiosas da familia, ou no vasto proscenio em que os voluntariosos conductores de rebanhos humanos, e os titeres doceis e flexiveis que thes ser vem de comparsas, representam a eterna comedia politica,-que se possa furtar á acção propulsora, ou reprimente, do direito?

A promessa de enlace balbuciada por dois corações que se amam e a lucta de exterminio travada entre dois povos que se odeiam; o obolo da beneficencia, que traduz a renuncia espontanea e generosa de um direito, e a espoliação da orphandade que exprime as impias machinações de uma ambição criminosa; o esforço paciente e rude do infatigavel e humilde operario e os deslumbrantes triumphos ruidosos, que são os galardões de um alto merecimento, ou as conquistas faceis de uma audacia aventureira e petulante; a explosão selvagem dos sentimentos egoisticos e o devotamento disciplinado dos sentimentos sociaes, a honra e a ignominia; a riqueza e a miseria; a vida e a morte; o heroismo e o crime; tudo é sanccionado, punido, permittido, prohibido, limitado, ou dominado pelo direito.

Por toda a parte e sempre a energia coordenadora do direito. Fus, eternumque jus.

Determinação de relações tão vastas e complexas, estudo de leis tão necessarias, comprehende-se bem porque a sciencia do direito, em todos os periodos de actividade mental e progresso litterario, tem merecido a mais desvelada solicitude, manifestada na organisação das escolas que a ensinam.

Não vos recordarei a influencia civilisadora irradiada pelas academiạs e universidades, onde um logar saliente foi sempre reservado á jurisprudencia, desde 
as escolas de Constantinopla e de Beryto ate as famosas universidades medievaes, e desde esses poderosos institutos de ensino ate as universidades e academias do nosso tempo.

Dos fins do seculo XII, ou, com mais segurança, dos primeiros alvores do seculo XIJI em deante, a historia da instrucção universitaria na Europa é uma não interrompida narrativa das conquistas da sciencia juridica, que, no dizer de Lerminier, foi a unica sciencia social que durante tres seculos a Europa cultivou. E foram as univesidades, - - na Italia as de Bolonha, Padua, Pisa, Perugia, Modena, Ferrara e tantas outras; na França a de Paris, que, no conceito de Ernesto Lavisse, era a alma mater das universidades do mundo. a projectar sobre as nações que se formavam a autoridade moral, intellectual e politica, da França, e as de Orléans, Tolosa e Bourges; a de Salamanca na Hespanha, a de Oxford na Inglaterra e a de Coimbra em Portugal,- - as activas officinas em que apparelhavam suas armaduras os jovens combatentes do direito.

Nem acreditemos que as academias e universidades tenham limitado seu efficaz e salutar influxo ao papel de poderosos propulsores do progresso scientifico do direito.

Desde que ao ferreo dogmatismo medievo se foram a pouco e pouco substituindo o livre exame e os fecundos processos de investigação scientifica, e desde que se cumeçaram a delinear as agremiações de povos que são as actuaes nações da culta Europa, foi-se dilatando a missão dos institutos universitarios, que se converteram em poderosos e activos fócos de idéias liberaes e inapreciaveis factores de unificação nacional.

Propulsar o desenvolvimento scientifico, diffundir doutrinas liberaes e estreitar os vinculos que formam 
a unidade nacional,-eis a triplice funcção que, segundo o testemunho da historia, têm desempenhado as instituições universitarias, e especialmente as escolas superiores de direito.

A applicação constante dos processos da comparação e generalisação ao estudo dos costumes locaes foi levantando sobre a diversidade das normas consuetudinarias a unidade do direito nacional. E a unificação do direito é um dos elementos mais efficazes para a conservação da unidade nacional.

A abstracção das imperfeições das leis existentes, por esse modo comparadas ás leis possiveis-processo logico tão ao sabôr das ardentes intelligencias juvenis, - foi suggerindo novas concepções ideaes da liberdade. E essas concepções, si algumas vezes não passam de sonhos irrealisaveis de uma imaginação indomavel, não raro são os prenuncios de uma grande conquista liberal.

Tão fundo se arraigou no animo dos pensadores e estadistas europeus a convicção de que o papel dos institutos universitarios é esse que acabei de delinear--vos, que não me seria difficil ir buscar na historia contemporanea exemplos innumeraveis, comprovativos de minha asserção.

Não receiasse eu abusar de vossa captivante e habitual gentileza, e haveria de mostrar-vos com Izoulet que, quando em I 436 pensou em frmar seu dominio na Normandia, a Inglaterra fundou a universidade de Caen, quando em I 572 quiz consolidar-se nos Paizes-Baixos, a Hespanha fundou a universidade de Douai; quando, depois de I870, accommetteu a empresa arriscada de germanisar a Alsacia-Lorena, a Allemanha reconstituiu a universidade de Strasbourgo; quando em 1828 reconheceu a necessidade de crear 
um fóco para suas opiniões, o partido liberal da Inglaterra fundou a universidade de Londres; quando em I 834 quiz luctar efficazmente contra a influencia do catholicismo conservador, o partido liberal da Belgica fundou a universidade de Bruxellas; quando em I 8 ro, quatro annos depois da memoravel batalha de Iena, tratou de reerguer-se de seu esmagamento militar e politico, a Allemanha fundou a Universidade de Berlim.

E são notaveis, meus jovens collegas, e merecem aqui ser lembradas as nobres palavras que então proferiu o rei da Prussia, quando nas ruas de Berlim ainda se ouvia o clangor dos clarins dos francezes: «E' preciso, disse Frederico Guilherme, é preciso que o Estado suppra por meio de forças intellectuaes as forças physicas que perdeu».

Nenhuma nação mais do que a Allemanha, observa insuspeito o laureado professor, e ninguem na Allemanha mais do que os principes da casa de Hohenzollern tem tido uma clara intuição da utilidade dos institutos universitarios. Ao lançar ás urtigas seu manto de grao-mestre da ordem teutonica, Alberto de Hohenzollern inaugurou a universidade de Kœnigsberg. Ao tomar posse dos primeiros dominios que a Prussia occupou sobre o Rheno, o grande eleitor creou a universidade de Duisburgo. Ao ver Heidelberg, o velho sanctuario da sciencia allemã, destruido pela invasão dos francezes, o successor de Frederico Guilherme organisou a universidade de Brandeburgo.

Pode-se dizer que em todos os momentos decisivos de sua historia a Allemanha tem fundado universidades e academias.

E vós todos sabeis o que vale e o que pode a Allemanha pelo pensamento e pela espada. 
Fôra superfluo multiplicar os exemplos. Por toda a parte e sempre que tem residido nos cimos do poder um pensamento liberal e creador, a organisação das escolas superiores tem sido uma das mais graves preoccupações daquelles a quem foi confiada a auctoridade suprema.

Nenhum chefe de Estado digno desse nome, nenhum estadista que pense no prestigio e no esplendor de sua patria, nenhum pensador que cogite destes problemas vitaes para o futuro de um paiz, preconisou jamais a concepção acanhada dos que pretendem circumscrever a actividade official á tarefa, aliás necessaria, de miristrar os primeiros rudimentos da instrucção.

Pois que! Interpretar caracteres graphicos e saber traçal-os, - simples instrumento para a acquisição de ideas verdadeiras, sãs, justas e uteis,-poderá offerecer-nós algum proveito, si essas idéas não forem elaboradas e divulgadas por intelligencias que um prolongado estudo e diuturna meditação tenham preparado para tão nobre e glorioso mistér?

A creação de instituiçoés de ensıno superior em que se professasse a sciencia do direito devia, naturalmente, ser um dos mais ardentes anhélos da primitiva patria brasileira, e, por isso, a I I de agosto de 1827 o generoso e patriotico ideal foi traduzido na mais fecunda realidade.

Dizer o que têm sido desde então as duas $\mathrm{Fa}$ culdades brasileiras, lembrar-lhes o passado, suas tradições e suas glorias, fôra avivar sómente o que está na consciencia reconhecida de todos nós.

Bastará recordar-vos apenas que, não fosse a lingua que fallamos tão ignorada nos mais cultos centros do velho e do novo continente, e, não raros d'en- 
tre os estadistas, jurisconsultos, litteratos, poetas e oradores, que passaram sob estas arcadas, ou na poetica e formosa Olinda, e no bravo e patriotico Recife, os mais bellos dias de sua juventude, veriam seus nomes aureolados por tão rutilante gloria, como a daquelles que desfructam uma indiscutida reputação universal.

Apague-se a historia das academias juridicas do Brasil, e a historia da nação brasileira será um enigma.

Entretanto, senhores, em torno dessas duas academias tem-se ouvido, nos ultimos tempos, um surdo rumor de vozes adversas, que não poucas vezes se alteam até se converterem em formaes increpações e ameaças de exterminio.

Não cuideis que eu pretenda referir-me ao tradicional adversario dos institutos scientificos, áquelle que desde a época de Bacon tem sido sempre um dos mais pervicazes e funestos embaraços ao progresso das universidades e academias, e que o immortal auctor do Novum Organum baptisou com a denominação de politicorum supercilium, isto é, a indifferença frivola dos politicos de vistas curtas,

Não quero alludir tão pouco aos glorificadores do passado á custa das detracções do presente. Estes não se cançam de proclamar, na linguagem fatigada dos velhos espiritos ankylosados na doce beatitude serena que thes dá a incapacidade de observar e raciocinar, que foi nas duas academias que ensaiaram os seus primeiros vôos a aguias de mais potente envergadura que têm adejado pelo firmamento da litteratura patria, ou que poisaram nas culminancias da politica nacional. Mas, hoje, não descobrindo entre os jovens neophytos do direito, que apenas se iniciam 
nos primeiros segredos de tão avara sciencia, os nomes laureados que uma longa tradição faz respeitar, retribuem com largueza a injustiça com que os velhos, de ordinario, são julgados pelos moços, que, segundo um subtil analysta da psychologia juvenil, "paragonandosi con noi, non paragonano già sé stess quali sono, ma il grand'uomo immaginario che ciascuno di loro crede fermissimamente di avere ad essere un giorno.»

São outros os nossos adversarios de hoje, mais activos e petulantes.

Em primeiro logar, os audazes remodeladores empiricos do direito, os ruminadores incorrigiveis das obsoletas endrominas requentadas de João Jacques Rousseau, para os quaes as nações são equiparaveis ás miseras cobaias em que o physiologista aventura toda sorte de experiencias que a imaginação lhe suggere.

Democratas de viellas, Desmoulins de fancaria. Dantons de opereta, grotescas imitações, parodias imprestaveis de antiquados originaes, já de si ridiculos e funestos, elles acreditam vêr nas velhas academias um importuno antemural opposto ás idéas impensadas e ás exoticas reformas com que pretendem subverter a sociedade, acreditando talvez que a felicitam. Dahi as continuas accusações de conservatorismo que nos atiram.

Temos, em segundo logar, os discipulos de uma seita scientifico-religiosa que, explorando o nome e as aberrações de um grande philosopho, que foi uma das mais potentes e fecundas organisações scientificas deste seculo, e para cuja gloria immarcessivel bastava o facto de ter unificado todas as provincias do saber humano sob o poderoso instrumento do methodo positivo, que elle demonstrou ser o unico methodo applicavel a todas as sciencias,-depois de escorraçada de todos os cantos da Europa pela ironia mordaz dos 
homens de espirito e pela repulsa austera dos homens de bom senso, transpoz o Atlantico, e, aproveitandose da anarchia mental que lavra nos paizes novos como o nosso, aqui installou seu centro de pregações e de combates.

Alimentando-se e vivendo exclusivamente do ridiculo, talvez para o fim de justificarem o paradoxo de um escriptor de espirito,_il fut un temps oú le ridicule tuait, aujour-d'hui on en vit,-os novos orientadores, da humanidade para cada instituição juridica propõem uma reforma disparatada; para cada problema social uma solução irrisoria; para cada um dos males da sociedade um remedio absurdo; em meio de cada controversia da imprensa diaria um novo desconchavo; em reposta a cada idéa bôa que se agite um dislate suprehendente.

Por isso, todos elles e seus discipulos mais ou menas orthodoxos não pódem tolerar a legitima influencia da classe dos juristas.

Aos primeiros eu direi, reproduzindo as palavras de um jurisconsulto proeminente, que foi talvez a mais fulgente gloria da litteratura juridica do Brasil: "alargai vossos espiritos, são a ignorancia e o erro que devem subir á sciencia e á verdade, e não estas que devem descer ao contentamento dos paladares, ou por medo de continuadas injustiças, ou para aplacar juizos desfavoraveis.»

Enganais-vos, si porventura suppondes que são os corpos docentes das academias que oppõem barreiras á avalanche de irreflectidas concepções juridicas que se despenham da empinada montanha de vossa burlesca vaidade.

Quem se vos oppõe é a sciencia, e ao lado da sciencia o bom senso. 
Foram a sciencia e o bom senso que na Republica Franceza, tendo de renovar-se em 1897 (notai bem, renovar-se apenas) o privilegio do seu primeiro instituto de credito, fizeram Burdeau, um intemerato democrata, estudar e offerecer em $\mathrm{I} 892$ o respectivo projecto de lei, para ser examinado, debatido e meditado durante seis longos annos; foram a sciencia e o bom senso que obrigaram a Allemanha, berço de insignes jurisconsultos, a estudar desde I 874 até r 896 o seu projecto de codigo civil, quando os incumbidos de estudal-o eram homens da estatura de Windscheid, Kúbel, Weber e Planck; foram a sciencia e o bom senso que só permittiram que a Italia promulgasse o seu novo codigo penal «dopo la lunga gestazione ben nota e senza esempio in altri paesi», conforme observou um dos eximios collaboradores dessa lei; são a sciencia e bom senso que na Confederação Helvetica têm demorado a realisação das aspirações nacionaes de unificação do direito de todo o paiz.

As sciencias sociaes não têm retortas; não se conhecem labboratorios de sociologia; a observação e a comparação são as unicas bases de suas generalisações, e a observação carece de ser paciente e diuturna, e a comparação é difficultosa e emmaranhada pela multiplicidade das circumstancias que revestem os factos.

Não é licito substituir as leis com a mesma frequencia e anciedade com que o enfermo varia as posições em um leito de dôres cruciantes.

Aos segundos redarguirei:-si, como apregoais, não são os legistas competentes para a direcção politica da sociedade, porque a sciencia que elles aprendem é um edificio sem base, maior e mais notavel é a incompetencia das outras classes, que, extranhas 
ás sciencias juridicas e sociaes, se devotam ao estudo das sciencias inferiores, porque o seu preparo scientifico é uma base sem edificio.

Estou de accôrdo comvosco unicamente sobre um ponto: quer me convença com o doce scepticismo artistico de Ernesto Renan que não convém torturar muito a verdade, que nada se ganha com importunal-a todos os dias, e que o philosopho deve ter um pouco de confiança na bondade infinita, e evitar inuteis açodamentos; quer acredite com o mavioso cantor das «Primeiras Meditações» que:

«Il est sous la nature, il est au fond des cieux,
Quelque chose d'obscur et de mystérieux,
Que la nécessité, que la raison proclame,
Et que voit seulmente la foi, cet œil de I'âme»;

quer pense, com um dos ultimos laureados pelas palmas academicas em França, que a religião é a sciencia da immensa maioria instinctiva, assim como a sciencia é a religião da pequena minoria pensante; quer exclame com o poeta-philosopho, Darmesteter;

«Fragilité des choses qui sont!

E'tervité des choses qu'on réve!»

-a realidade é fragil e transitoria, eterno é sómente o sonho; creio comvosco na utilidade, ou necessidade, de uma religião.

Mas, si a religião e necessaria, mantenhamos a que foi sempre abraçada pela immensa maioria da nação, a que a tem sempre consolado nas angustias e nas dôres, e sanctificado todos os jubilos e victorias nacionaes, a religião daquelle que, na phrase de um dos seus adoradores sem fé, ha de ser sempre o evocador dos incomparaveis sonhos, o magico dos eternos adeuses, mestre das consolações inesperadas, principe dos perdões infinitos. 
Senhores, ao lado da identidade de origem, de tradições, de religião, de lingua, de interesses, necessidades e aspirações, o direito é um dos vinculos mais fortes da nacionalidade.

Conserval-o, pois no Brasil sempre uno, e intangivel ás tendencias dispersivas das circumscripções territoriaes, é dever que se impõe a todos nós.

Ao exito de encargo tão patriotico importa que não toleremos um só dos elementos dissolventes da homogeneidade de nossas leis.

Desloque-se do poder nacional a inapreciavel attribuição de ministrar e dirigir o ensino da sciencia do direito, anime-se em cada Estado da União a formação de grotescos arremedos de academias e universidades, tanto mais propagadores de doutrinas subversivas e sequiosos de impensadas innovações, quanto mais espessa fồr a crôsta de sua ignorancia, e teremos talvez lançado, o primeiro germen da idéa sacrilega da pulverisação do direito brasileiro.

Guardemos, pois, as nossas tradicionaes academais com o mesmo caracter nacional que ellas têm tido até o presente.

Nem siquer nutramos o vão receio de que nellas se depare a mais tenue barreira aos progressos do direito e da liberdade.

Não se divulgou jámais neste paiz um idéal generoso e patriotico que aqui não fosse acariciado e festejado, uma só rẻforma pensada e conveniente que aqui não recebesse nossos applausos convencidos, uma só conquista da liberdade que não saudassem as palmas de todos nós, mestres e discipulos.

Não afroux̣emos um só dos laços preciosos que mantêm a unidade fecunda desta gigantesca e formosa nação. 
E procedamos assim, para que, em vez de Estados autonomiros, prosperos, pacificos, tranquillos e respeitados sob a força e as garantias tutelares do poder nacional, não tenhamos um dia de desencavar

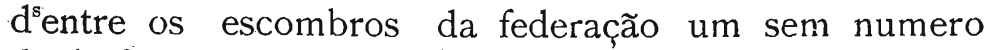
de imformes agrupamentos, irrequietos, fracos, depauperados, agitados e revoltos em hostis rivalidades, accesos em luctas continuadas, mesquinhas e estereis, -fragmentos impalpaveis de uma vasta e rutilante nebulosa que foi.

A sagrada e patriotica tarefa incumbe a todos nós; mas, ella especialmente vos compete, meus jovens collegas, a vós que, em meio dos desalentos da hora presente, symbolizais a esperança de um roseo porvir, e sobre quem «o Brasil ergue a fé»---Trabalhai por erguerdes de pé «este immenso colosso gigante».

(Prolongada e estrepitosa salva de palmas. O orador é calorosamente felicitado.) 